\title{
Erratum to: Pregnancy Outcomes Following In Utero Exposure to Lamotrigine: A Systematic Review and Meta-Analysis
}

\author{
Gali Pariente $^{1} \cdot$ Tom Leibson $^{1} \cdot$ Talya Shulman $^{1} \cdot$ Thomasin Adams-Webber $^{2}$. \\ Eran Barzilay $^{3} \cdot$ Irena Nulman $^{1}$
}

Published online: 17 May 2017

(c) Springer International Publishing Switzerland 2017

\section{Erratum to: CNS Drugs DOI 10.1007/s40263-017-0433-0}

An Online First version of this article was made available online at http://link.springer.com/journal/40263/ onlineFirst/page/1 on 22 April 2017. An error was subsequently identified in the article, and the following correction should be noted:

Page 1, abstract, column 2, lines 2-6: The following sentence, which previously read:
“... in utero exposure to lamotrigine monotherapy was found to be associated with significantly decreased rates of inborn defects (odds ratio [OR] 1.15; 95\% confidence interval [CI] 0.62-2.16 and OR 1.25; 95\% CI 0.89-1.74, respectively)." should read:

" ... in utero exposure to lamotrigine monotherapy was not found to be associated with significantly increased rates of inborn defects (odds ratio [OR] 1.15; 95\% confidence interval [CI] 0.62-2.16 and OR 1.25; 95\% CI 0.89-1.74, respectively)."

The online version of the original article can be found under doi:10.1007/s40263-017-0433-0.

Gali Pariente

galipa@bgu.ac.il

1 Division of Clinical Pharmacology and Toxicology, The

Hospital for Sick Children, University of Toronto, 555

University Avenue, Toronto, ON M5G 1X8, Canada

2 Hospital Library, The Hospital for Sick Children, Toronto, ON, Canada

3 Department of Obstetrics and Gynecology, Chaim Sheba Medical Center, Tel Hashomer, Affiliated with the Sackler Faculty of Medicine, Tel Aviv University, Tel Aviv, Israel 